\title{
ULTRASOUND-GUIDED BIOPSY IN FOCAL LIVER LESIONS
}

\author{
Madalina ILIE ${ }^{1,2}$, Mihaela RUSU ${ }^{1}$, Cristian G. ROSIANU ${ }^{3}$, Tiberiu P. NEAGU ${ }^{2,4}$, \\ Ion G. MOTOFEI ${ }^{2,5}$, Ovidiu G. BRATU ${ }^{2,6}$, Bogdan SOCEA ${ }^{2,5}$, Ana Maria A. STANESCU ${ }^{2}$, \\ Florentina GHERGHICEANU², Anca PANTEA STOIAN ${ }^{7}$, Ruxandra OPRITA ${ }^{1,2}$, \\ Camelia DIACONU ${ }^{2,8} \bowtie$
}

${ }^{1}$ Department of Gastroenterology, Clinical Emergency Hospital of Bucharest, Romania

2 "Carol Davila“ University of Medicine and Pharmacy, Bucharest, Romania

${ }^{3}$ Department of Gastroenterology, „Sfanta Maria“ Clinical Hospital, Bucharest, Romania

${ }^{4}$ Department of Plastic Surgery, Clinical Emergency Hospital of Bucharest, Romania

${ }^{5}$ General Surgery Clinic, Emergency Clinical Hospital „Sfântul Pantelimon“, Bucharest, Romania

${ }^{6}$ Department of Urology, Emergency Universitary Central Military Hospital, Bucharest, Romania, Academy of Romanian Scientists

7 "Carol Davila“ University of Medicine and Pharmacy, Diabetes, Nutrition and Metabolic Diseases, Bucharest, Romania

${ }^{8}$ Department of Internal Medicine, Clinical Emergency Hospital of Bucharest, Romania

Received 14 June 2018, Accepted 21 July 2018

https://doi.org/10.31688/ABMU.2018.53.3.08

\section{Abstract}

Introduction. Focal liver lesions represent one of the main indications of ultrasound-guided liver biopsy.

The objective of the study was to evaluate the advantages and risks of liver biopsy, and to highlight the importance of a close follow-up in the prevention of postprocedural complications.

Methods. We have retrospectively analyzed a number of 52 patients, who underwent liver biopsies in the Clinical Emergency Hospital of Bucharest, Romania, after being diagnosed with various types of focal liver lesions through ultrasound scanning.

Results. Regarding the quality of the bioptic samples obtained: $98 \%$ of them were diagnostic, only $2 \%$ being nondiagnostic, mainly due to the tissue necrosis found within the tumor. The majority of the cases selected

\section{Résumé}

Biopsie guidée par ultrasons dans les lésions focales du foie

Introduction. Les lésions hépatiques focales représentent une des indications principales pour la biopsie hépatique.

L'objectif de l'étude est d'évaluer les avantages et les inconvénients de la biopsie hépatique et de souligner l'importance de la surveillance approfondie du patient dans la phase post-biopsie pour la prévention des complications.

Méthodes. Nous avons analysé rétrospectivement un nombre de 52 patients qui ont été biopsiés dans le département de gastroentérologie de l'Hôpital d'Urgence - Bucarest, après avoir été diagnostiqués avec 
for the study had multiple liver lesions (70\%), the rest of $30 \%$ had single lesions identified by ultrasound scanning. After histopathological analysis, in $89 \%$ of the cases the lesion proved to be malignant (of which $70 \%$ were hepatic metastases and $30 \%$ were liver carcinomas), the rest of $11 \%$ were benign. This last category included hepatic adenomas and focal nodular hyperplasia, identified in young female population. Our study did not reveal any relation between the location of the lesion within the liver and the number of needle passes needed in order to obtain viable biopsy specimens $(\mathrm{P}=0.16)$. Of all the cases that underwent liver biopsy, only $4 \%$ had complications, mainly minor bleeding and only $1 \%$ major bleeding and transitory hypotension. There was no case of death registered.

Conclusions. Ultrasound guided percutaneous liver biopsy is a fast, economical and user-friendly procedure, frequently used in the diagnosis of focal liver lesions. The success rate of the biopsy in obtaining viable samples is high and it depends more on the structure of the lesion and the materials used, rather than on the anatomical localization of the lesion within the liver. Severe complications can be avoided if a close follow-up of the patients is performed.

Keywords: liver biopsy, focal liver lesion, liver carcinoma, focal nodular hyperplasia, ultrasound.

\section{INTRODUCTION}

Focal liver lesions are a relatively frequent diagnosis, found in ultrasound (US) practice. They could be classified into 3 categories, according to the histopathological characteristics ${ }^{1}$ :

- benign lesions that do not imply any treatment: hepatic hemangioma, focal nodular hyperplasia (FNH), benign liver cyst, and focal fat sparing;

- benign lesions that imply obligatory treatment: hepatic adenoma, adenomatosis, liver abscess, echinococcal cyst, granulomatous inflammation;

- malignant lesions: hepatocellular carcinoma (HCC), cholangiocarcinoma, liver metastases from other primary sites, biliary cystadenocarcinoma, hepatic angiosarcoma and lymphoma. de diverses lésions hépatiques focales en utilisant le scanning aux ultrasons.

Résultats. En ce qui concerne la qualité des pièces biopsiques obtenues $98 \%$ ont été diagnostiques tandis que $2 \%$ n' ont pas pu mettre en évidence le diagnostic en raison de la nécrose des tissus dans la lésion hépatique. La plupart des cas sélectionnés pour l'étude ,70\% d'eux ont été diagnostiqués avec des lésions multiples et le reste de $30 \%$ avec des lésions uniques. Après l'analyse histopathologique, les résultats ont montré que $89 \%$ des patients ont des lésions malignes (70\% des métastases hépatiques, $30 \%$ - des carcinomes du foie). Le reste d'entre eux (11\%) ont été diagnostiqués avec des lésions bénignes. Dans cette dernière catégorie est incluse l'hyperplasie nodulaire focale et l'adénome hépatique identifié dans la jeune population féminine. Notre étude n'a pas identifié une relation entre l'emplacement de la lésion et le nombre de passage des aiguilles requises pour obtenir des biopsies viables $(\mathrm{p}=0.16)$. De tous les cas seulement $4 \%$ ont souffert des complications, constituées surtout d'hémorragies mineures et 1\% d'hémorragies majeures ou d'hypotension transitoire. Il n'y avait pas de cas de décès.

Conclusions. La biopsie hépatique guidée par échographie est une procédure rapide et économique fréquemment utilisée dans les cas de lésion hépatique focale. Le taux de réussite de la biopsie dans l'obtention de fragments viables est élevé et il dépends plus de la structure de la lésion et des matériaux utilisés que de la localisation de la lésion dans le foie. Les complications graves peuvent être évitées si la surveillance approfondie post-biopsie est assurée.

Mots-clés: biopsie hépatique, lésion hépatique focale, carcinome du foie, hyperplasie nodulaire focale, ultrasons.

The role of ultrasound-guided percutaneous hepatic biopsy for the evaluation of focal hepatic disease has been highlighted throughout the years. US guidance is a more approachable technique for liver biopsy, in comparison with computed tomography (CT) guidance. US-guided biopsies are easier to perform, less expensive and do not expose the patient to the risk of radiation.

Absolute contraindications to liver biopsy include diseases that influence the patient's ability to stand still during the procedure, and vascular lesions such as hemangiomas, bleeding disorders (INR > 1.5 and severe thrombocytopenia) ${ }^{2,3}$.

Relative contraindications include anemia (hemoglobin level less than $7 \mathrm{~g} / \mathrm{dL}$ ), ascitic fluid present in all the peritoneal recesses, biliary obstruction, peritonitis and right pleural effusion ${ }^{4,5}$. 


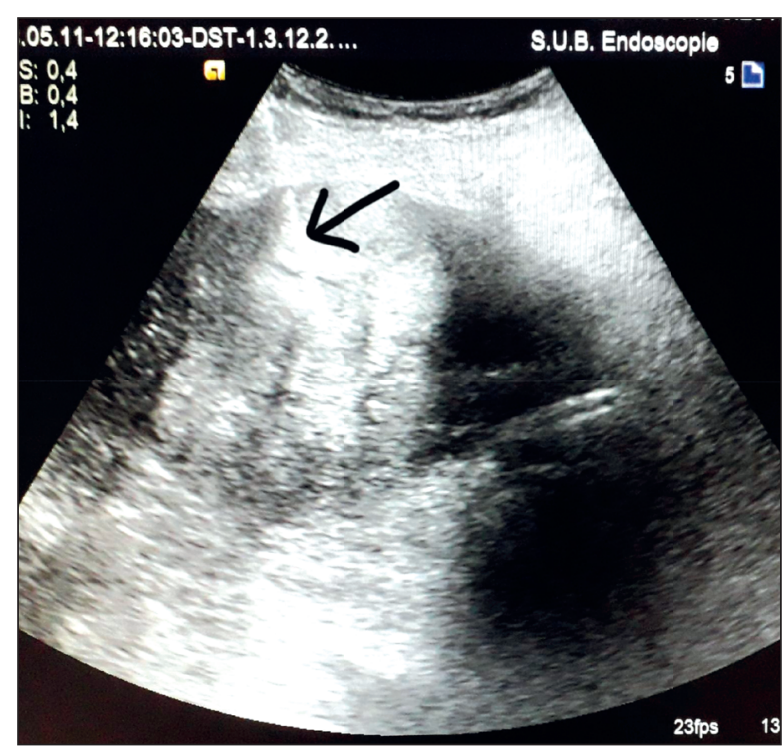

Figure 1. The insertion of the biopsy needle, under ultrasonographic guidance, into a large solid,

inhomogenous mass, situated in the VIth hepatic segment. The blood tests revealed an Alpha-fetoprotein $>500 \mathrm{U} / \mathrm{mL}$. The histopathological analysis confirmed that the bioptic sample belonged to a hepatocarcinoma.

The obJective OF OUR STUdY was to establish the advantages and disadvantages of liver biopsy, depending on the chosen technique. We aimed to search the particular aspects of the hepatic lesions which may have a high influence on the results of hepatic biopsy, and the importance of a close postprocedural follow up for the prevention of short or long term complications $^{6,7}$.

\section{Matherials AND Methods}

The retrospective descriptive study has been performed in the Clinical Emergency Hospital of Bucharest, Romania, and included 52 patients hospitalized between January $1^{\text {st }}$, 2014-December 31 $31^{\text {st }}$, 2017. The focal liver lesions have been diagnosed using abdominal US scanning, followed by image-guided percutaneous liver biopsy.

The study included a number of 52 patients, predominantly man, aged between 28 and 84 years old, who performed US-guided percutaneous hepatic biopsies in our hospital. The mean age of the studied group was 56 years. An informed consent has been signed by all the participants in the study. The liver biopsies were performed by specifically-trained gastroenterologists. Coagulation tests were performed and the majority of patients met the standardized coagulation criteria (platelet count greater than $60,000 / \mu \mathrm{L}$ and international normalized ratio less than 1.5). Patients

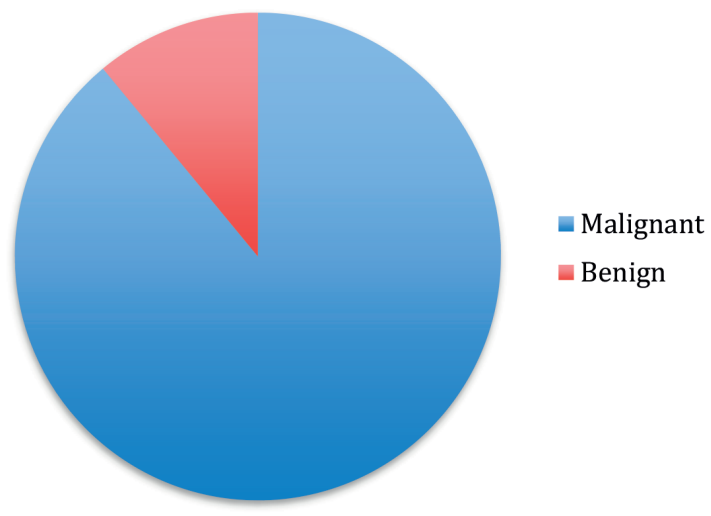

Figure 2. Distribution of hepatic lesions according to histopathological result.

with altered coagulation tests received, prior to the biopsy, platelet transfusion or several units of fresh frozen plasma. The majority of lesions were located in the right liver lobe and measured between $3-19 \mathrm{~cm}$. Biopsy specimens were obtained using an automated biopsy gun, having an 18-Gauge needle diameter (ULTIMATE PM18-20 Biopsy Needle, Zamar Biopsy, Croatia). The needle was advanced into the lesion under real-time US guidance. When dealing with large tumors, the needle was inserted into the periphery, to avoid central necrosis and further complications. Before the procedure, an ultrasound scan enabled the practician to decide on the safest needle trajectory, in order to adjust the patient's position, for reaching the lesion precisely and avoiding the pleura. The patients were sedated with midazolam and the selected entry site was prepared by proper skin disinfection and injection of a local anesthetic (2\% lidocaine solution). An average of 2 needle passes were performed in most of the patients, in order to obtain viable fragments, for histopathological exams ${ }^{8,9}$. A final ultrasound scan completed the procedure, to reveal the possible early complications, such as hematoma. The patients were placed in the right lateral position, tamponading the site of the puncture, in order to avoid bleeding. The majority of the patients were already hospitalized ${ }^{10}$ . The ones that were not previously hospitalized remained in our unit for further monitoring (approx. 24 hours) and, if no complications have been noticed, the patients were discharged ${ }^{11}$.

\section{Results}

Biopsy specimens proved to be diagnostic in $98 \%$ of the cases. Only 2\% of them were nondiagnostic, mainly due to the fact that the tumor contained an important amount of necrotic tissue $e^{12-14}$. 
The majority of the cases selected for US-guided biopsy had multiple lesions (70\%), while the rest of $30 \%$ had single lesions.

After histopathological analysis, in $89 \%$ of the cases the lesions proved to be malignant, the rest of $11 \%$ were benign (Figure 2). The malignant lesions were hepatic metastases ( $70 \%$ cases), mainly liver metastases from a colonic adenocarcinoma or breast cancers and hepatocarcinomas in 30\% of the cases. The benign cases were represented mainly by focal nodular hyperplasia and hepatic adenoma, which were detected in the young female population included in the study.

Our study did not find any relation between the anatomical location of the lesion within the liver and the number of needle passes needed in order to obtain viable tissue for the histopathological analysis $(p=0.16)$.

In $4 \%$ of liver biopsies, complications occurred. Minor bleeding has been registered as the main consequence. Only $1 \%$ of the cases developed major bleeding and transitory arterial hypotension ${ }^{15-18}$. No deaths have been registered.

\section{Discussion}

Previous studies have shown many advantages of US-guided liver biopsy in the diagnosis of focal liver lesions ${ }^{19,20}$. Among the numerous advantages of this technique, the following can be mentioned: the user-friendly instrument - using an $18 \mathrm{G}$ automatic biopsy gun which can be held easily by the practician, and the fact that the type of needle used by the biopsy gun targets easily even the hardest to reach and smallest lesions, due to its rigidity (in comparison with a more flexible needle, with smaller caliber, which tends to bend and modify its position) $)^{21,22}$.

In our study, the anatomical distribution of the lesion within the liver was not an impediment in obtaining high accuracy samples, whereas the size of the lesion had a higher impact on the quality of the bioptic material. Smaller lesions tend to be more homogenous, while larger masses may contain more necrotic areas.

The postprocedural complication rate was low, mainly due to the close follow up of the patients. They have been attentively monitored after biopsy, using repeated ultrasound scans and hemoglobin level testing. They were monitored even in the absence of clinical manifestations of hemorrhage $e^{23,24}$.

Regarding the small percentage of patients who had major bleeding after percutaneous biopsy, the standard imaging technique chosen for evaluating the extension of complications was CT scanning. In the majority of the cases, urgent angiography was performed, with further embolization of the vessel responsible for the active hemorrhage.

The histopathological results obtained showed that the majority of the tissue samples was malignant, belonging to hepatic metastases from colorectal cancers or breast cancers. The majority of the patients with malignant lesions also had ascites with peritoneal carcinomatosis ${ }^{25-27}$.

One of the important contraindications for liver biopsy is abundant ascites ${ }^{28.30}$. The medical staff performed a paracentesis prior to the procedure in each case reported with an important amount of ascitic fluid in all peritoneal recesses ${ }^{31-33}$.

\section{Conclusions}

Ultrasound-guided percutaneous liver biopsy is one of the fastest, economical and user-friendly procedures, easily applicable in the diagnosis protocol of focal liver lesions. The success rate of the biopsy in obtaining viable samples is high and it depends more on the structure of the lesion and the technical quality of materials used, rather than on the anatomical distribution of the lesions within the liver. Severe complications can be avoided if a close follow up of the patients is performed ${ }^{34}$. The most common complications after liver biopsy are the following: minor bleeding, mild pain and minor decrease in blood pressure.

\section{Compliance with Ethics Requirements:}

„The authors declare no conflict of interest regarding this article"

„The authors declare that all the procedures and experiments of this study respect the ethical standards in the Helsinki Declaration of 1975, as revised in 2008(5), as well as the national law. Informed consent was obtained from all the patients included in the study"

„No funding for this study"

\section{References}

1. Nahla MAH, Khaled FZ, Mohamad HAE, Heba RH. Benign versus malignant focal liver lesions: Diagnostic value of qualitative and quantitative diffusion weighted MR imaging. The Egyptian Journal of Radiology and Nuclear Medicine 2016, 47(6):1211-1220.

2. Tchelepi H, Ralls PW. Ultrasound of focal liver masses. Ultrasound Q, 2004, 20:155-169.

3. Saloura EA, Vasiliki B, Theodoropoulos E, Kalokairinou M, Balanika AP, Baltas CS. Focal hepatic lesion ultrasound-guided biopsies. Medical Ultrasonography, 2010,12(4): 295-299.

4. Appelbaum L, Kane RA, Kruskal JB, Romero J, Sosna J. Focal hepatic lesions: US-guided biopsy - lessons from 
review of cytologic and pathologic examination results. RSNA Radiology, 2009,250(2):453-458

5. Yu SC, Lau WY, Leung WT, Liew CT, Leung NW, Metrewel C. Percutaneous biopsy of small hepatic lesions using an 18 gauge automated needle. Br J Radiol 1998,71(846):621- 624.

6. Moulton JS, Moore PT. Coaxial percutaneous biopsy technique with automated biopsy devices: value in improving accuracy and negative predictive value. Radiology, 1993, 186:515-522.

7. Caturelli E, Giacobbe A, Facciorusso D. Percutaneous biopsy in diffuse liver disease: increasing diagnostic yield and decreasing complication rate by routine ultrasound assessment of puncture site. Am J Gastroenterol, 1996, 91(7):1318-1321.

8. Wee A. Fine needle aspiration biopsy of the liver: Algorithmic approach and current issues in the diagnosis of hepatocellular carcinoma. Cytojournal, 2005, 2(1):1-16.

9. Yu SC, Liew CT, Lau WY, Leung TW, Metreweli C. US-guided percutaneous biopsy of small (or $1 \mathrm{~cm}$ ) hepatic lesions. Radiology, 2001,218(1):195-199.

10. Livraghi T, Torzilli G, Lazzaroni S, et al. Biopsia percutanea con ago sottile delle lesioni focali. In: Torzilli G, Olivari N, Livraghi T, et al. Ecografia in Chirurgia 1997, 1:167-190.

11. Calarasu C, Nitu M, Grecu VI, et al. Hepatic and splenic tuberculosis in a patient with severe imunosupression and neurological complications. Arch Balk Med Union, 2016, 51(1):108-113.

12. Francque SM, De Pauw FF, Van den Steen GH, Van Marck EA, Pelckmans PA, Michielsen PP. Biopsy of focal liver lesions: guidelines, comparison of techniques and cost-analysis. Acta Gastroenterol Belg, 2003, 66(2):160-165.

13. Caturelli E, Solmi L, Anti M, et al. Ultrasound guided needle biopsy of early hepatocellular carcinoma complicating liver cirrhosis: a multicentre study. Gut, 2004, 53:1356-1362.

14. Buscarini L, Bolondi L, Colombo P, Livraghi $\mathrm{T}$ et al. Ultrasound-guided fine-needle biopsy of focal liver lesions: techniques, diagnostic accuracy and complications: a retrospective study on 2091 biopsies. Journal of Hepatology, 1990, 11(3):344-348

15. Piccininio F, Sagnelli E, Pasquale G, et al. Complications following percutaneous liver biopsy. J Hepatol, 1986,2(2):165173.

16. Sparchez Z. Complications after percutaneous liver biopsy in diffuse hepatopathies. Romanian Journal of Gastroenterology, 2005, 14(4):379-384.

17. McGill DB, Rakela J, Zinsmeister AR, Ott Bj. A 21-year experience with major hemorrage after percutaneous liver biopsy. Gastroenterology, 1990, 99:1396-1400.

18. Al-Leswas D, O’Reilly DA, Poston GJ. Biopsy of solid liver tumors: adverse consequences. Hepatobiliary Pancreat Dis Int, 2008, 7:325-327.

19. Dusenbery D Ferris JV, Thaete FL, Carr BI. Percutaneous ultrasound-guided needle biopsy of hepatic mass lesions using a cytohistologic approach: comparison of two needle types. Am J Clin Pathol, 1995, 104:583-587.

20. Cresswell AB, Welsh FKS, Rees M. A diagnostic paradigm for resectable liver lesions: to biopsy or not to biopsy? HPB Journal, 2009, 11:533-540.

21. Jones OM, Rees M, John TG, Bygrave S, Plant G. Biopsy of resectable colorectal liver metastases causes tumor dissemination and adversely affects survival after liver resection. $\mathrm{Br}$ J Surg, 2005, 92:1165-1168.

22. Gilmore IT, Burroughs A, Murray-Lyon IM, Williams R, Jenkins D, Hopkins A. Indications, methods, and outcomes of percutaneous liver biopsy in England and Wales: an audit by the British Society of Gastroenterology and the Royal College of Physicians of London. Gut, 1995, 36:437-441.

23. Smith EH. Complications of percutaneous abdominal fine-needle biopsy. Review. Radiology, 1991, 178:253-258.

24. Durand F, Regimbeau JM, Belghiti J, et al. Assessment of the benefits and risks of percutaneous biopsy before surgical resection of hepatocellular carcinoma. J Hepatol, 2001, 35:254-258.

25. Marsh JW, Dvorchik I. Should we biopsy each liver mass suspicious for hepatocellular carcinoma before liver transplantation? Yes. J Hepatol, 2005, 43:558-562.

26. Mitchell DG. Focal manifestations of diffuse liver disease at MR imaging. Radiology, 1992, 185:1-11.

27. Ohlsson B, Nilsson J, Stenram U, Akerman M, Tranberg KG. Percutaneous fine-needle aspiration cytology in the diagnosis and management of liver tumours. Br J Surg, 2002, 89:757-762.

28. Diaconescu D, Pantea Stoian A, Socea L, et al. Hepato-renal syndrome: a review. Arch Balk Med Union, 2018, 53(2):239-245.

29. Drăghici T, Negreanu L, Bratu OG, et al. Liver abnormalities in patients with heart failure. Arch Balk Med Union, 2018, 53(1):76-81.

30. Bucur D, Berceanu D, Diaconu C. Hemostasis in patients with cirrhosis: a hazardous balance. Arch Balk Med Union, 2016, 51(4):501-505.

31. Fornari F, Filice C, Rapaccini GL, et al. Small $(<3 \mathrm{~cm})$ hepatic lesions. Results of sonographically guided fine-needle biopsy in 385 patients. Dig Dis Sci, 1994, 39:2267-2275.

32. Bottles K, Cohen MB. An approach to fine-needle aspiration biopsy diagnosis of hepatic masses. Diagn Cytopathol, 1991, 7:201-204.

33. Nazarian LN, Feld RI, Herrine SK, et al. Safety and efficacy of sonographically guided random core biopsy for diffuse liver disease. J Ultrasound Med, 2000, 19(8): 537-541.

34. Berceanu D, Bucur D, Diaconu C. Type 2 diabetes and liver disease: a frequent and harmful connection. Arch Balk Med Union, 2016, 51(4):506-511. 